\title{
25 Research Square \\ Diversity of the BoLA-DRB3 Gene in Cattle Breeds From Tropical and Subtropical Regions of South America
}

\section{Magali Nicole Valenzano}

INTA: Instituto Nacional de Tecnologia Agropecuaria https://orcid.org/0000-0002-8428-3962

María Eugenia Caffaro

Instituto Nacional de Tecnología Agropecuaria: Instituto Nacional de Tecnologia Agropecuaria

Veronica Viviana Lía

Instituto Nacional de Tecnología Agropecuaria: Instituto Nacional de Tecnologia Agropecuaria

Mario Poli

Instituto Nacional de Tecnología Agropecuaria: Instituto Nacional de Tecnologia Agropecuaria

Silvina Elizabeth Wilkowsky ( $\sim$ wilkowsky.silvina@inta.gob.ar)

Instituto Nacional de Tecnología Agropecuaria: Instituto Nacional de Tecnologia Agropecuaria

\section{Research}

Keywords: BoLA-DRB3, genetic diversity, peptide-binding region, zebuine, mixed-breeds.

Posted Date: March 2nd, 2021

DOI: https://doi.org/10.21203/rs.3.rs-251864/v1

License: @ (i) This work is licensed under a Creative Commons Attribution 4.0 International License. Read Full License 


\section{Abstract \\ Background}

Bovine leukocyte antigens (BoLA) are widely used as markers of disease and immunological traits in cattle because of their primary function in the recognition of pathogens by the immune system. To date, however, the characterization of BoLA gene polymorphisms in Latin American Zebu and mixed zebuine breeds is scarce. By a sequence-based typing method, here we sequenced exon 2 of BoLA class II DRB3 gene of 264 animals from the five breeds (Creole, Brahman, Braford, Brangus and Nellore) most commonly used in northern Argentina.

\section{Results}

The taurine and zebuine breeds contained 61 previously reported alleles. Genetic diversity was high at allelic and molecular levels, particularly in the mixed breeds. Neutrality tests revealed that none of the breeds shows the even gene frequency distribution expected under a balanced selection scenario. The $\mathrm{F}_{\mathrm{ST}}$ index shows significant differences across all populations $\left(\mathrm{F}_{\mathrm{ST}}=0.052, \mathrm{P}<0.001\right)$, indicating a substantial differentiation between breeds. UPGMA trees and Metric multidimensional scaling (MDS) analysis show that, as expected, Creole is distantlyrelated to the other zebuinebreeds. Among them, Brahman, Braford and Brangus cluster closer together than with Nellore. These data are consistent with the historical and geographical origin of these breeds. A peptide binding region sequence analysis at the aminoacid level revealed that, despite the nucleotide diversity among the breeds, the key aminoacids involved in peptide recognition are greatly conserved.

\section{Conclusions}

This is the first report of BoLA-DRB3 diversity in pure and mixed zebuine cattle breeds from Argentina. Knowledge ofBoLA-DRB3 variability in breeds adapted to tropical and subtropical environments contributes not only to ongoing efforts to catalog bovine MHC allele frequencies by breed and location but also to the design of peptidebased vaccines.

\section{Background}

Increasing livestock productivity requires the use of breeds adapted to specific environments, as this helps the animals to cope with stress and enhances their resistance to circulating pathogens. In this sense, the production, reproduction and survival of cattle breeds in tropical and subtropical climates are seriously compromised by heat stress and enzootic infectious diseases.

According to the United States Department of Agriculture (USDA), Argentina is the third larger producer of bovines worldwide, with a population of 53.8 million heads (1). The breeds Nellore, Brahman, Brangus and Braford are the most widely used by farmers in northern Argentina,which is the second major productivity zone in the country. The selection of these breeds is because of their natural adaptationto the agro-ecological conditions of this subtropical region $(2,3)$.

The major histocompatibility complex (MHC) has an essential role in the adaptiveimmune system, and comprises the cell surface glycoproteins necessary for Tlymphocytesto recognize antigenic peptides on the surface of 
antigen-presenting cells (4). In addition, the MHC genetic variability in native breeds is of great interest in evolutionary biology because of the typically high levels of polymorphism and because of its involvement in host defences against pathogens. Consequently, the MHC allelic diversity of representative species of several mammalian orders, including Artiodactyla, Perissodactyla, Carnivora, Primates, and Rodentia has been thoroughly characterized (5).

The bovine MHC, called Bovine Leucocyte Antigen (BoLA), is encoded in chromosome 23 and consists of three gene classes, I, II and III. MHC class II products are normally expressed by cells of the immune system, namely macrophages, dendritic cells, B and T lymphocytes. In bovines, BoLA class II genes are distributed in two distinct regions, lla and Ilb. The $D R A, D R B, D Q A$ and $D Q B$ genes are located in the lla region, whereas the $D O B, D Y A, D Y B$ and $D I B$ genes are in the IIb region (6). In particular, the DR and DQ molecules represent the main class II restriction elements for CD4-positive T-helper cells (7). Among them, the BoLA-DRB3 gene is the only one known to be fully functional (4) and is the most polymorphic class II locus in cattle. This gene product influences the magnitude and epitope specificity of antigen-specific T-cell responses to infectious diseases. Accordingly, differences in susceptibility to different diseases (i.e. dermatophilosis, bovine leucosis virus-induced lymphocytosis and mastitis), production traits (i.e. milk production) and vaccine responses (i.e. foot-and-mouth disease and Theileria parva infection) (8-11) have been associated with BoLA-DRB3 polymorphisms. There is compelling evidence that in mammals the MHC polymorphism is maintained by some form of overdominance or balancing selection (12, 13).

The polymorphism of BoLA-DRB3 genes occurs predominantly at residues within the peptide-binding groove (14). In cattle, 357 BoLA-DRB3 alleles have been identified in various breeds up to date; which are listed in the Immune Polymorphism Database (IPD) - MHC database (15). Although seemingly high, this number of alleles encompasses only 12 out of over 800 breeds of cattle recognized worldwide (16). To a large extent, the breeds studied to date include European taurine (i.e., Hereford, Angus, Shorthorn, Holstein, Jersey), Asian taurine (Japanese Black, Philippine Native, and Korean Native), American Creole (i.e., Yacumeño and Hartón del Valle) and different types of cross-breeds (i.e ., Holstein $\times$ Sahiwal, Philippine Native $\times$ Brahman and Philippine Native $\times$ Holstein)(16).

In this context, we aimed at gaining further knowledge about the genetic diversity of the BoLA-DRB3 gene in Argentine populations of pure Bos indicus types Brahman and Nellore as well as in the mixed breeds Braford and Brangus, as genetic data of these breeds arestill scarce. We have also investigated the levels and structuring patterns of BoLA allelic variation and the functional diversity of the peptide binding region (PBR) in all these breeds.

\section{Methods}

\section{Animals and genomic DNA extraction}

Blood, hair or semen samples were obtained from 205 Bos indicus bovines: Nellore $(N=30)$ and Brahman $(N=36)$, as pure breeds, as well as Braford $(\mathrm{N}=70)$ and Brangus $(\mathrm{N}=69)$, as mixed breeds. Individuals $(\mathrm{N}=59)$ of the Creole breed (Bostaurus) were added as a different non-related breed, i.e. as an outgroup. The sampled individuals were selected to avoid genetic relatedness and to obtain the maximum representativeness of the breed. The genealogical records and historical data of the formation of the different herds were taken into consideration for the analysis. The procedure for sample collection was approved (protocol number 35/2010) by the Institutional 
Committee for Care and Use of Experimental Animals of the National Institute of Agricultural Technology (CICUAEINTA). All procedures were performed according the guidelines described in the institutional manual. Additional file 1 displays detailed information about all the analyzed breeds.

Whole blood was obtained by venipuncture using EDTA as anticoagulant. Genomic DNA was extracted using a commercial kit (AxyPrep Blood Genomic DNA Miniprep Kit, Axygen Biosciences, Union City, CA) according to the protocol supplied by the manufacturer. Genomic DNA from bull semen was obtained from frozen straws using a standard phenol-chloroform-based extraction method. DNA isolation from hair root samples was done using a commercial kit (NucleoSpin® Tissue, Macherey-Nagel, Germany) according to the manufacturer's instructions. In all cases DNA quantity and quality were determined by measuring its UV absorption at 260 and $280 \mathrm{~nm}$ and the 260/280 and 260/230 absorbance ratios using a NanoDropTM 1000 spectrophotometer (Thermo Scientific, Wilmington, Delaware, USA). The purified DNA was stored in aliquots at $-20^{\circ} \mathrm{C}$ until use.

\section{BoLA-DRB3 typing usingPCR-sequence basedtyping (PCR-SBT)}

PCR reactions were performed in a Mastercycler (Eppendorf $\left.{ }^{\circledR}\right)$ thermocycler in a final volume of 15 ul. The volume mixture contained6 ng of genomic DNA, 0.03 X PCR buffer (Mg2 + plus), 0.3 mM of each primer (HL030; 5'ATCCTCTCTCTGCAGCACATTTCC-3', and HL032; 5'- TCGCCGCTGCYCAGTGAAACTCTC - 3') (17), 0.2 mM of dNTPs, 0.75 U Paq5000® DNA Polymerase (Agilent Technologies, Stratagene, USA) and Milli Q grade water up to the total volume. The conditions for amplification were $94^{\circ} \mathrm{C}$ for $3 \mathrm{~min}$, followed by 35 cycles of $20 \mathrm{~s}$ at $94^{\circ} \mathrm{C}, 20 \mathrm{~s}$ at $60^{\circ} \mathrm{C}$ (annealing temperature) and $1 \mathrm{~min}$ at $72^{\circ} \mathrm{C}$. The reactions were finished with a $72^{\circ} \mathrm{C}, 5$-min extension. Amplified fragments of 247 pbc orresponding to exon 2 of the BoLA-DRB3 gene were visualized in a 1\% agarose gel and sequenced using BigDye ${ }^{\circledR}$ chemistry on an $A B I 3130 x \mid$ sequencer (Applied Biosystems) following the manufacturer's protocol. The sequencing reactions were performed in both senses using the same primers as for PCR reactions, in a total volume of $10 \mathrm{ul}$ containing a 1:10 dilution of the PCR product as template and $0.1 \mathrm{mM}$ of each of the corresponding primer, in addition to the mix and buffer $5 \mathrm{X}$ of the BigDye $\AA$ Terminator kit. Sequence analysis and genotype calling were performed using Haplofinder $(8,18)$. Briefly, this program uses all known DRB3 alleles to create a list of all possible heterozygous combinations using IUPAC ambiguity codes. Haplofinder compares the consensus sequence obtained with the list of all possible combinations list.Alignments were constructed using T-Coffee (19). Additional file 2 displays the list of detected alleles and theirlPD-MHC database accession numbers.

\section{Statistical analysis}

\subsection{Measures of genetic variability}

Allele frequencies and number of alleles $(\mathrm{Na})$ were obtained by the direct count method. The effective (Ne) and observed (No) number of allelesas well asthe observed $(\mathrm{Ho})$ and expected unbiased heterozygosity (He) for the BoLA-DRB3 locus were estimated according to Nei (1978)using Genalex (21). Potential deviations from HardyWeinberg equilibrium (HWE) were assessed for each breed by FIS statistics (22) using the exact test included in GENEPOP (23), whereas allelic richness was estimated using FSTAT 2.9.3.2 (24).

The number of segregating sites(S), total number of mutations (Eta), number of haplotypes (h), haplotype diversity $(\mathrm{Hd})$, nucleotide diversity $(\pi)$, and the average number of nucleotide differences $(k)$ were calculated using DnaSP 5.00 .02 (25).Tajima's D test(26) was used for testing the null hypothesis of neutrality (27). The statistical significance of Tajima's D was calculated using a two tailed test and the coalescent simulations algorithm 
implemented in DnaSP 5.00.02(25). The mean number of nonsynonymous ( $\mathrm{dN}$ ) and synonymous (dS) nucleotide substitutions per site was estimated for each pair using the Jukes-Cantor's formula as described by Nei and Gojobori using DnaSP 5.00.02. The Z-test was used for assessing the dN/dS ratio significance using MEGA X (28).

The distribution of alleles across major groups of breeds was represented by a Venn plot using the R package 'VennDiagram' (29). For this analysis,we used the data generated here as well as information from previous reports on other south American breeds (16, 30-32)(Additional file 1). In the case of the dataset of Kelly et al.(2002) only the alleles whose PCR-RFLP pattern matched with only one allele in the current nomenclature (33) were used.

\subsection{PBR aminoacid analysis}

Aminoacid identity and similarity percentages were calculated with Geneious Prime 2020.2.4(33) using a BLOSUM62 substitution matrix. Computations were performed based on the aminoacid sequence of the 31 putative positions constituting the MHC-DRB PBR (35). A logo of PBR positions for each population was created using WebLogo software(36). The height of symbols within the stack indicates the relative frequency of each aminoacid at that position for each population. Only alleles having frequencies greater than $5 \%$ were considered in the analysis. The R 4.0.2 package (29) was used to calculate Pearson correlation coefficients (PCC) among breeds and to perform a metric multidimensional scaling (MDS) on the correlation matrix obtained.

\subsection{AMOVAanalysis}

The partitioning of genetic variation among breeds was performed withan analysis of molecular variance (AMOVA) (37) considering either the sequences or the discrete allelic states of BoLA-DRB3 genotypes. In the case of sequence analyses, the evaluations were performed based on pairwise differences using Arlequin 3.11 (38). For discrete allelic states, Nei's genetic distances were used as the starting matrix for AMOVA. Statistical significance of each variance component was assessed based upon 999 permutations of the data.

\subsection{Genetic distances, cluster analysis and metric multidimensional scaling}

Genetic structure and genetic differentiation among breeds were assessed using Wright's F statistics using the variance-based method of Weir and Cockerham (22). These parameters and their significance were assessed with FSTAT 2.9.3.2. Nei's genetic distance was calculated from allele frequencies using GENALEX (21). Cluster analysis was performed using the unweighted pair group method with arithmetic mean (UPGMA) algorithm implemented in Phylip (39). The generated trees were visualized with Figtree (40). Further examination of the relationships among breeds were assessed by using Nei's genetic distances to perform a MDS analysis using R (29).

\section{4- Phylogenetic analysis}

Phylogenetic analysis was performed by constructing Maximum Likelihood (ML) trees from BoLA-DRB3 nucleotide sequences. Prior to ML analyses, the computer program ModelTest 2.1.9 (41) was used to select the most appropriate model of molecular evolution according to the Akaike Information Criterion. The sequences were analyzed under a Jukes-Cantor model with gamma rate heterogeneity and invariant sites. ML tree searches were performed with PAUP 4.0 (42). Node robustness was assessed with 1000 bootstrap replicates.

\section{Results}


To determine the diversity and distribution of BoLA-DRB3 alleles in cattle breeds from North Eastern Argentina, we genotyped 264 individuals using PCR-SBT and therefore identified 61 previously reported alleles, with no new allelic variants (Table 1). Of these 61 variants, five are present only in $B$. taurus, four are present exclusively in $B$. indicus and 22 are present exclusively in mixed breeds. Only nine alleles are shared betweenthe three major bovine types. Meanwhile, the remaining 21 alleles are shared between at least two breeds. All breeds presented exclusive alleles (Additional file 3). 
Table 1

Frequencies of BoLA-DRB3 alleles detected by PCR-SBT.

\begin{tabular}{|c|c|c|c|c|c|c|}
\hline DRB3.2 Allele & $\begin{array}{l}\text { Creole }(\mathrm{N} \\
=59)\end{array}$ & $\begin{array}{l}\text { Nellore } \\
(\mathrm{N}=30)\end{array}$ & $\begin{array}{l}\text { Brahman }(\mathrm{N} \\
=36)\end{array}$ & $\begin{array}{l}\text { Braford }(\mathrm{N} \\
=69)\end{array}$ & $\begin{array}{l}\text { Brangus } \\
(\mathrm{N}=70)\end{array}$ & Reference \\
\hline BoLA-DRB3*001:01 & 0.203 & & & 0.022 & 0.171 & $\begin{array}{l}\text { Mikko\& } \\
\text { Anderson,(43) }\end{array}$ \\
\hline BoLA-DRB3*002:01 & 0.017 & & & 0.014 & 0.164 & $\begin{array}{l}\text { Takeshima et } \\
\text { al., (44) }\end{array}$ \\
\hline BoLA-DRB3*003:01 & 0.008 & & & 0.007 & & $\begin{array}{l}\text { Mikko\& } \\
\text { Anderson, (43) }\end{array}$ \\
\hline BoLA-DRB3*005:01 & 0.068 & & 0.014 & 0.022 & 0.007 & $\begin{array}{l}\text { Mikko\& } \\
\text { Anderson, (43) }\end{array}$ \\
\hline BoLA-DRB3*005:02 & 0.008 & & & & & $\begin{array}{l}\text { Mikko\& } \\
\text { Anderson, (43) }\end{array}$ \\
\hline BoLA-DRB3*005:04 & & & & 0.007 & & $\begin{array}{l}\text { Takeshima et } \\
\text { al., (45) }\end{array}$ \\
\hline BoLA-DRB3*007:01 & 0.008 & & 0.042 & 0.014 & 0.007 & $\begin{array}{l}\text { Takeshima et } \\
\text { al., (44) }\end{array}$ \\
\hline BoLA-DRB3*008:01 & & & & 0.036 & 0.029 & $\begin{array}{l}\text { Mikko\& } \\
\text { Anderson, (43) }\end{array}$ \\
\hline BoLA-DRB3*009:01 & & & & 0.021 & 0.021 & $\begin{array}{l}\text { Mikko\& } \\
\text { Anderson, (43) }\end{array}$ \\
\hline BoLA-DRB3*009:02 & 0.008 & & 0.014 & 0.014 & 0.007 & $\begin{array}{l}\text { Mikko\& } \\
\text { Anderson, (43) }\end{array}$ \\
\hline BoLA-DRB3*010:01 & & & & & 0.007 & $\begin{array}{l}\text { Mikko\& } \\
\text { Anderson, (43) }\end{array}$ \\
\hline BoLA-DRB3*010:02 & & & & 0.094 & 0.007 & $\begin{array}{l}\text { Mikko\& } \\
\text { Anderson, (43) }\end{array}$ \\
\hline BoLA-DRB3*011:01 & 0.051 & & & 0.007 & 0.021 & $\begin{array}{l}\text { Takeshima et } \\
\text { al., (44) }\end{array}$ \\
\hline BoLA-DRB3*011:03 & & 0.017 & & 0.007 & & $\begin{array}{l}\text { Maillard et al., } \\
\text { (46) }\end{array}$ \\
\hline BoLA-DRB3*012:01 & 0.034 & 0.017 & 0.194 & 0.065 & & $\begin{array}{l}\text { Mikko\& } \\
\text { Anderson, (43) }\end{array}$ \\
\hline BoLA-DRB3*013:01 & 0.025 & & & 0.014 & & $\begin{array}{l}\text { Mikko\& } \\
\text { Anderson, (43) }\end{array}$ \\
\hline $\begin{array}{l}\text { BoLA- } \\
\text { DRB3014:01:01 }\end{array}$ & & & & 0.014 & 0.021 & $\begin{array}{l}\text { Mikko\& } \\
\text { Anderson, (43) }\end{array}$ \\
\hline BoLA-DRB3*014:02 & & & & & 0.007 & $\begin{array}{l}\text { De S \& Sing, } \\
\text { (47) }\end{array}$ \\
\hline BoLA-DRB3*015:01 & 0.017 & & & 0.051 & 0.043 & $\begin{array}{l}\text { Mikko\& } \\
\text { Anderson, (43) }\end{array}$ \\
\hline
\end{tabular}




\begin{tabular}{|c|c|c|c|c|c|c|}
\hline DRB3.2 Allele & $\begin{array}{l}\text { Creole }(\mathrm{N} \\
=59)\end{array}$ & $\begin{array}{l}\text { Nellore } \\
(\mathrm{N}=30)\end{array}$ & $\begin{array}{l}\text { Brahman }(\mathrm{N} \\
=36)\end{array}$ & $\begin{array}{l}\text { Braford }(\mathrm{N} \\
=69)\end{array}$ & $\begin{array}{l}\text { Brangus } \\
(\mathrm{N}=70)\end{array}$ & Reference \\
\hline BoLA-DRB3*015:02 & & & & 0.007 & & Xu A et al.,(48) \\
\hline BoLA-DRB3*016:01 & & 0.033 & & 0.051 & & $\begin{array}{l}\text { Mikko\& } \\
\text { Anderson, (43) }\end{array}$ \\
\hline BoLA-DRB3*016:02 & & & & & 0.007 & $\begin{array}{l}\text { Mikko et al., } \\
(49)\end{array}$ \\
\hline BoLA-DRB3*017:01 & & & & & 0.014 & $\begin{array}{l}\text { Mikko\& } \\
\text { Anderson,(43) }\end{array}$ \\
\hline BoLA-DRB3*017:03 & & & & & 0.021 & $\begin{array}{l}\text { Maillard et al., } \\
\text { (46) }\end{array}$ \\
\hline BoLA-DRB3*018:01 & 0.110 & 0.017 & & 0.043 & 0.029 & $\begin{array}{l}\text { Takeshima et } \\
\text { al., (44) }\end{array}$ \\
\hline BoLA-DRB3*019:01 & & & 0.014 & & & $\begin{array}{l}\text { Mikko\& } \\
\text { Anderson, (43) }\end{array}$ \\
\hline BoLA-DRB3*019:02 & & & & & 0.007 & $\begin{array}{l}\text { Takeshima et } \\
\text { al., (45) }\end{array}$ \\
\hline $\begin{array}{l}\text { BoLA- } \\
\text { DRB3020:01:02 }\end{array}$ & 0.042 & & 0.042 & 0.007 & & $\begin{array}{l}\text { Gelhaus et al., } \\
\text { (50) }\end{array}$ \\
\hline BoLA-DRB3*020:03 & 0.059 & & & & & $\begin{array}{l}\text { Maillard et al., } \\
(46)\end{array}$ \\
\hline BoLA-DRB3*021:01 & 0.042 & & & & & $\begin{array}{l}\text { Mikko\& } \\
\text { Anderson, (43) }\end{array}$ \\
\hline BoLA-DRB3*022:01 & & 0.083 & 0.069 & 0.022 & & $\begin{array}{l}\text { Mikko\& } \\
\text { Anderson, (43) }\end{array}$ \\
\hline BoLA-DRB3*023:01 & 0.085 & & & & & $\begin{array}{l}\text { Mikko\& } \\
\text { Anderson, (43) }\end{array}$ \\
\hline BoLA-DRB3*024:03 & & & & 0.007 & & \\
\hline BoLA-DRB3*026:01 & 0.008 & & & & & $\begin{array}{l}\text { Mikko\& } \\
\text { Anderson, (43) }\end{array}$ \\
\hline BoLA-DRB3*027:03 & & & & 0.043 & 0.007 & $\begin{array}{l}\text { Takeshima et } \\
\text { al., (44) }\end{array}$ \\
\hline BoLA-DRB3*027:04 & & & & & 0.014 & $\begin{array}{l}\text { Gelhaus et al., } \\
\text { (50) }\end{array}$ \\
\hline BoLA-DRB3*027:05 & & & 0.028 & & & $\begin{array}{l}\text { Maillard et al., } \\
(46)\end{array}$ \\
\hline BoLA-DRB3*027:07 & & & & 0.022 & 0.021 & $\begin{array}{l}\text { Maillard et al., } \\
\text { (46) }\end{array}$ \\
\hline BoLA-DRB3*027:10 & & & & & 0.021 & $\begin{array}{l}\text { Takeshima et } \\
\text { al., (51) }\end{array}$ \\
\hline
\end{tabular}

Total number of alleles: 61. Most frequent alleles in each breed are highlighted in bold. 


\begin{tabular}{|c|c|c|c|c|c|c|}
\hline DRB3.2 Allele & $\begin{array}{l}\text { Creole }(\mathrm{N} \\
=59)\end{array}$ & $\begin{array}{l}\text { Nellore } \\
(\mathrm{N}=30)\end{array}$ & $\begin{array}{l}\text { Brahman }(\mathrm{N} \\
=36)\end{array}$ & $\begin{array}{l}\text { Braford(N } \\
=69)\end{array}$ & $\begin{array}{l}\text { Brangus } \\
(\mathrm{N}=70)\end{array}$ & Reference \\
\hline BoLA-DRB3*028:01 & 0.076 & 0.100 & & 0.065 & & $\begin{array}{l}\text { Gelhaus et al., } \\
\text { (50) }\end{array}$ \\
\hline BoLA-DRB3*028:02 & & & & 0.007 & & $\begin{array}{l}\text { Takeshima et } \\
\text { al., (45) }\end{array}$ \\
\hline BoLA-DRB3*029:01 & 0.025 & 0.017 & & & & $\begin{array}{l}\text { Gelhaus et al., } \\
\text { (50) }\end{array}$ \\
\hline BoLA-DRB3*030:01 & & 0.100 & 0.375 & 0.087 & 0.121 & $\begin{array}{l}\text { Gelhaus et al., } \\
(50)\end{array}$ \\
\hline BoLA-DRB3*030:21 & & 0.017 & & & 0.021 & $\begin{array}{l}\text { Takeshima et } \\
\text { al., (44) }\end{array}$ \\
\hline BoLA-DRB3*030:22 & & & 0.014 & & & $\begin{array}{l}\text { De S \& Sing, } \\
\text { (47) }\end{array}$ \\
\hline BoLA-DRB3*031:01 & & & 0.042 & 0.014 & 0.014 & $\begin{array}{l}\text { Takeshima et } \\
\text { al., (44) }\end{array}$ \\
\hline BoLA-DRB3*032:01 & & 0.017 & & 0.036 & 0.050 & $\begin{array}{l}\text { Takeshima et } \\
\text { al., (52) }\end{array}$ \\
\hline BoLA-DRB3*032:02 & & 0.116 & 0.028 & & 0.007 & $\begin{array}{l}\text { Takeshima et } \\
\text { al., (45) }\end{array}$ \\
\hline BoLA-DRB3*032:03 & & & & & 0.007 & $\begin{array}{l}\text { Maillard et al., } \\
(46)\end{array}$ \\
\hline BoLA-DRB3*033:01 & & & & 0.022 & 0.043 & Sitte et al., (53) \\
\hline BoLA-DRB3*034:01 & & & 0.014 & 0.014 & & $\begin{array}{l}\text { Takeshima et } \\
\text { al., (44) }\end{array}$ \\
\hline BoLA-DRB3*035:01 & 0.017 & 0.183 & 0.014 & 0.007 & 0.007 & $\begin{array}{l}\text { Maillard et al., } \\
\text { (46) }\end{array}$ \\
\hline BoLA-DRB3*036:01 & 0.034 & 0.233 & 0.042 & 0.065 & 0.043 & $\begin{array}{l}\text { Maillard et al., } \\
\text { (46) }\end{array}$ \\
\hline BoLA-DRB3*037:01 & & 0.017 & & & & $\begin{array}{l}\text { Takeshima et } \\
\text { al., (52) }\end{array}$ \\
\hline BoLA-DRB3*039:01 & & & 0.014 & & & \\
\hline BoLA-DRB3*042:01 & & & 0.028 & 0.029 & 0.007 & $\begin{array}{l}\text { Maillard et al., } \\
(46)\end{array}$ \\
\hline BoLA-DRB3*043:01 & & & & 0.007 & & $\begin{array}{l}\text { Maillard et al., } \\
(46)\end{array}$ \\
\hline BoLA-DRB3*044:01 & 0.034 & & & 0.014 & & $\begin{array}{l}\text { Maillard et al., } \\
1999\end{array}$ \\
\hline BoLA-DRB3*048:01 & 0.017 & & & & 0.007 & $\begin{array}{l}\text { De S \& Sing, } \\
\text { (47) }\end{array}$ \\
\hline
\end{tabular}

Total number of alleles: 61. Most frequent alleles in each breed are highlighted in bold. 


\begin{tabular}{|c|c|c|c|c|c|c|}
\hline DRB3.2 Allele & $\begin{array}{l}\text { Creole }(\mathrm{N} \\
=59)\end{array}$ & $\begin{array}{l}\text { Nellore } \\
(\mathrm{N}=30)\end{array}$ & $\begin{array}{l}\text { Brahman }(\mathrm{N} \\
=36)\end{array}$ & $\begin{array}{l}\text { Braford(N } \\
=69)\end{array}$ & $\begin{array}{l}\text { Brangus } \\
(\mathrm{N}=70)\end{array}$ & Reference \\
\hline BoLA-DRB3*048:02 & & & & 0.014 & & $\begin{array}{l}\text { Takeshima et } \\
\text { al., (45) }\end{array}$ \\
\hline BoLA-DRB3*057:02 & & 0.033 & 0.014 & & 0.007 & Das et al., (54) \\
\hline Number of alleles & 23 & 15 & 18 & 37 & 34 & \\
\hline $\begin{array}{l}\text { Number of most } \\
\text { frequent alleles }\end{array}$ & 7 & 6 & 3 & 7 & 4 & \\
\hline
\end{tabular}

To better analyze allele distribution, we subsequently constructed a Venn diagram using a larger dataset of 70 alleles from ten breeds grouped in three major bovine types (Bos taurus, Bos indicus and mixed breeds) (see materials and methods and Additional file 1). The plot shows that 26 alleles (37.1\%) are shared by three major groups, whereas seven alleles (10\%) are present exclusively in Bos taurus, three (4.3\%) in Bos indicus and seven $(10 \%)$ in the mixed breeds (Fig. 1).

The identity of high frequency alleles $(>5 \%)$ also varies depending on the breed. Creole and Braford have the highest number of alleles above the $5 \%$ threshold $(n=7$ each), followed by Nellore $(n=6)$, Brangus $(n=4)$ and Brahman $(n=3)$. The allele*030:01 is the only high-frequency allele that is shared by almost all breeds, except for Creole (Table 1). Only the alleles *035:01 and *036:01 are shared by all the breeds.

\section{2-BoLA-DRB3 diversity and Tajima'sD.}

The genetic diversity was assessed taking into account several parameters (Table 2). The Na ranges from 15 in Creole to 37 in Braford. It is noteworthy that in all the breeds the $\mathrm{Ne}$ is lower than the allelic richness. The He values ranges from 0.806 in Brahman to 0.953 in Braford, whilst the Ho values ranges from 0.643 in Brangus to 0.855 in Braford. Overall, Braford is the most diverse breed, as evidenced by the number of alleles, the heterozygosity and the allelic richness.

Table 2: Measures of genetic variability.

\begin{tabular}{|c|c|c|c|c|c|c|c|c|}
\hline & N & $\mathrm{Na}$ & $\mathrm{Ne}$ & Ho & $\mathrm{He}$ & uHe & $\mathrm{F}_{\mathrm{IS}}$ & Allelic richness \\
\hline Creole & 59 & 23 & 11.488 & 0.814 & 0.913 & 0.921 & $0.117^{\star}$ & 19.113 \\
\hline Nellore & 30 & 15 & 7.531 & 0.733 & 0.867 & 0.882 & $0.170^{\star}$ & 15.000 \\
\hline Brahman & 36 & 18 & 5.153 & 0.694 & 0.806 & 0.817 & $0.152^{\star}$ & 16.574 \\
\hline Braford & 69 & 37 & 21.350 & 0.855 & 0.953 & 0.960 & 0.110 & 27.108 \\
\hline Brangus & 70 & 34 & 11.681 & 0.643 & 0.914 & 0.921 & $0.303^{\star}$ & 22.990 \\
\hline
\end{tabular}

The BoLA-DRB3 diversity was also examined at the DNA level using seven indexes (Table 3 ). The $\pi$ value varies from 0.074 in Nellore and Creole to 0.082in Braford. The ranking of $\mathrm{Hd}$ is in line with that of the He. The S number 
varies from 56 in Nellore and Brahman to 65 in Braford, whilst the number of mutations varies from 67 in Nellore to82 in Braford. All the breeds present more mutations than segregating sites; which shows that there are sites that do not conform to the infinite site model. The average number of nucleotide differences $(k)$ is lower in pure breeds than in mixed breeds, as expected because of their admixed nature. Tajima's D test shows no departures from neutral expectations.

In addition, we calculated the number of $\mathrm{dN}$ and $\mathrm{dS}$ for each breed (Table 3 ). The $\mathrm{dN}$ values ranges from 0.096 in Nellore and Brahman to 0.104 in Braford, whilst the dS values ranges from 0.024 in Nellore to 0.037 in Brahman, with a significant $\mathrm{dN} / \mathrm{dS}$ ratio $(\mathbb{\nabla 1})$ in all populations. The ratio between $\mathrm{dN}$ and $\mathrm{dS}$ is more pronounced when only considering PBR codons.

Table 3

Genetic diversity at the sequence level.

\begin{tabular}{|c|c|c|c|c|c|c|c|c|c|c|c|c|}
\hline & $\mathbf{N}$ & $S$ & Eta & $\mathrm{h}$ & $\mathrm{Hd}$ & $\pi$ & k & Tajima & Total & & PBR & \\
\hline & & & & & & & & & $d N$ & dS & $d N$ & dS \\
\hline Creole & 59 & 58 & 74 & 10 & 0.786 & 0.074 & 17.419 & 1.114 & 0.100 & $0.036 *$ & 0.217 & $0.082^{\star}$ \\
\hline Nellore & 30 & 56 & 67 & 15 & 0.882 & 0.074 & 17.356 & 0.701 & 0.096 & $0.024^{\star}$ & 0.197 & $0.051^{\star}$ \\
\hline Brahman & 36 & 56 & 68 & 10 & 0.817 & 0.076 & 17.924 & 0.930 & 0.096 & $0.037^{\star}$ & 0.198 & $0.072^{\star}$ \\
\hline Braford & 69 & 65 & 82 & 37 & 0.960 & 0.082 & 19.184 & 0.908 & 0.104 & $0.035^{\star}$ & 0.228 & $0.071^{*}$ \\
\hline Brangus & 70 & 62 & 76 & 33 & 0.918 & 0.078 & 18.108 & 0.989 & 0.097 & $0.035^{*}$ & 0.196 & $0.071^{\star}$ \\
\hline \multicolumn{13}{|c|}{$\begin{array}{l}\text { References: number of individuals ( }(\mathrm{N}) \text {, number of segregating sites (S), number of mutations (Eta), number of } \\
\text { haplotypes (h), haplotype diversity (Hd), nucleotide diversity ( } \mathrm{n} \text { ), mean number of pairwise differences } \\
\text { (k),Tajima's D Neutrality test, mean number of nonsynonymous (dN) and synonymous (dS) nucleotide } \\
\text { substitutions per site in the complete BoLA sequence (Total) and in the peptide binding site (PBR). The } \\
\text { asterisks indicate a statistically significantly different from } 1 \mathrm{dN} / \mathrm{dS} \text { ratio. }\end{array}$} \\
\hline
\end{tabular}

\section{3- PBR similarity analysis}

The BoLA-DRB3 PBR aminoacidic sequence was analyzed for each breed as an indicator of functional diversity. To this purpose, we assessed PBR position identity and similarity for all alleles (Additional file 4). According to the identity analysis, most (59/61) of the alleles possessa different PBR. Regarding similarity, Brahman and Brangus have the highest percentages (80.8\%), thus indicating low diversity in these mixed breeds. Conversely, Braford had the lowest similarity percentage (74.7\%), and it is the most diverse breed at the PBR level. This finding is consistent with the nucleotide diversity results. According to the PCC analysis and MDS, Braford is the most different breed at the PBR level in comparison to all the analyzed breeds (Fig. 2 B and C).

The logo representation of PBR shows very similar substitution patterns between breeds (Fig. 2A). The most variable positions were 11, 13, 37, 70, 71 and 74, as reported previously (Bohorquez et al., 2020). Aminoacids present at position 86 (binding pocket 1 ) are reported to frequently be either a valine $(\mathrm{V})$ or a glycine (G) (55). We also found phenylalanine (F) in this position, but only in the Nellore breed. Other study has previously reported the same result for this breed (4). Aminoacids frequently found in position 70 ofthe binding pocket 4 are frequently either glutamic acid (E), arginine (R) or glutamine (Q). Accordingly, in our samples we have found all these 
aminoacids. However, a high proportion of Brahman samples also presented aspartic acid (D). In the other binding pockets $(6,7$ and 9$)$, the aminoacids found in our samples are quite conserved as the ones already reported $(4,55)$.

\section{4-Genotypic frequencies of BoLA-DRB3 alleles and population structuring}

According to an analysis ofa potential deviations from HWE performed by computing FIS indexes for each breed, Creole, Nellore, Brahman and Brangus exhibit a significant excess of homozygotes, while Braford does not, although the FIS is also higher than zero (Table 2).

The $\mathrm{F}_{\mathrm{ST}}$ index was used to analyze the degree of genetic differentiation among the 5 breeds studied. This index shows significant differences for all cattle breeds $\left(F_{S T}=0.052, P<0.001\right)$ (Fig. 3A). Moreover, significant values are also observed for all pairwise comparisons $(P<0.001)$ with values ranging from 0.029 between Braford and Brangus to 0.117 between Brahman and Creole. These results demonstrate that, although rather low in most instances, there is significant genetic differentiation between all the breeds.

The analysis of the levels of genetic differentiation between breeds estimated using AMOVA reveals that the percentage of variation between breeds was $5.60 \%$ when alleles where coded as discrete states and $4.50 \%$ when the sequence divergence was included in the analysis $(P<0.001)$.

\section{5-Population relationships based on frequencies of BoLA-DRB3 alleles}

To determinethe genetic relationship between the breeds under study, we used genetic distances and a metric MDS (Fig. 3). In agreement with the historical and geographical origin of the breeds examined here, the genetic distance between the group of pure and mixed Bos indicus breeds and Creole is quite large (Fig. $3 \mathrm{~A}$ and B). Fig. 3C displays the results from the MDS and illustrates the first and second principal coordinates. The first two coordinates account cumulatively for $98.07 \%$ of the variability in the data. In accordance with the UPGMA tree (Fig. 3B), the first coordinate accounts for $77.30 \%$ of the total variance and shows a differentiation pattern between Creole (Bos taurus) and the other breeds. Brahman is located at the opposite end of this coordinate. The second coordinate explains $20.77 \%$ of the total variation and clearly distinguishes Nellore (Bos indicus) from the remaining breeds. The third coordinate (not shown in the figure) accounts for $1.93 \%$ of the variance and it fails to provide any information regarding the potential origin of the breeds.

\section{6-Phylogenetic analysis}

The phylogenetic analysis was performed by constructing Maximum Likelihood (ML) trees from BoLA-DRB3 nucleotide sequences (Additional file 5). The resulting tree shows no relationships between allele lineages and breeds. As expected, most clusters are formed according to their respective allele nomenclature, which is based on the nucleotide sequence $(10,33)$ and thus confirms the correct assignation of the alleles.

\section{Discussion}

Knowledge of MHC diversity has important implications for the improvement of animal health and breeding since histocompatibility molecules play a keyrole in pathogen recognition. Therefore, information about breeds frequently used in specific geographic regions and whose BoLA-DRB3 genetic background is currently unknown is crucial for the update of allele catalogues and the design of better breeding strategies. 
In this study, we report the BoLA-DRB3 diversity of five cattle breeds currently raised in northeast Argentina but that are also used in many temperate regions of south America. These breeds are selected by Argentine farmers because of their adaptation to the warm climate of the region as well as their natural resistance against certain diseases and arthropods, including the bovine tick Rhipicephalus microplus, which is widely distributed in the area $(2,3)$. This tick is the vector of pathogens such as the bacteria Anaplasma marginale and the protozoa Babesia bovis and Babesia bigemina (3). Some reports have associated certain BoLA-DRB3 alleles of pure and mixed breeds from tropical environmentswith susceptibility or resistance to these tick-borne diseases $(12,56)$. For instance, the alleles *042:01, *011:01 and *020:01:02 were associated with tolerance to $B$. bigemina infections, whilst the alleles *027:03 and *013:01 were linked to $B$. bigemina and $A$. marginale susceptibility, respectively. All these alleles occurred in low frequencies in the samples assessed in our study. This may be related toa bias in the types of breeds sampled for the research. It is noteworthy that the allele *011:01 was highly frequent in Creole, whereas the other alleles only occurred in low frequencies in Brangus and Braford. If $B$. bigemina tolerance alleles are further confirmed in other bovine populations, our data would reinforce the utility of characterizing BoLA-DRB3 diversity as a routine procedure of animal breeding programs.

The distribution of BoLA-DRB3 alleles reveals that frequencies differed significantly between breeds. All breeds haveexclusive alleles, suggesting that they are well differentiated populations with very low levels of gene flow.

An analysis of the expanded data matrix including data from Bos taurus, Bos indicus and mixed breeds from other Latin American countries shows that the exclusive alleles from mixed breeds decrease in comparison to our own data (Fig. 1) (Additional file 1). This may indicate that the Bos indicus individuals involved in the origin of the mixed breeds would be different from the ones that are present in the region today.

The genetic diversity within breeds was measured by the number of alleles, allelic richness and heterozigosity at the BoLA-DRB3 gene. In all the breeds, Ne is lower than the allelic richness, probably due to an uneven distribution of the allele frequencies. Overall, Braford is the most genetically diverse breed. Although the detected number of alleles was higher than those estimated for other south American cattle breeds $(4,31,57)$, the heterozigosity values obtained here are lower, indicating the contribution of low frequency alleles. An analysis of the genetic diversity at the nucleotide level retrieved similar results. In our data, the $\mathrm{Hd}, \pi$ and $\mathrm{k}$ values result higher in mixed breeds than in pure ones, thus showing that mixed breeds capture more diversity, as expected.

The diversity at PBR positions determines which peptides a given BoLA-DRB3 allele can bind and this information is crucial to increase peptide-histocompatibility complex affinity for peptide-based vaccine design. Despite the fact that Bos taurus and Bos indicus are well differentiated bovine types, our correlation analysis shows that they cluster together based on PBR aminoacid sequences. Moreover, the sequence analysis of binding pockets, the PCC and MDS show that with exception of Braford, the remaining breeds tend to have a similar peptide repertoire in the PBR, in spite of the observed genetic differentiation. This conservation extends to the breeds studied here, and is particularly evident in aminoacids at positions 70,71 , and 74 of pocket 4 , which occupies a central position within the peptide binding groove. These aminoacids have been implicated as playing a significant role in human immune responsiveness (58), but also correlated with vaccine responses and infectious disease susceptibility or tolerance in bovines $(55,59-61)$. In this sense, it could be hypothesized that eventhough bovine breeding programs make use of extensive crossing, there may be a functional constraint in the PBR to BoLA-DRB3 aminoacid variability. 
In order to assess the structuring of BoLA-DRB3variation, we computed Wright's fixation indices (22). Previous studies reportedboth positive and negative deviations from HWE in different breeds; which suggests an interplay between selection and inbreeding, or either that some breeds were more admixed than the others (57). Although the individuals selected for this research were not genetically related, the excess of homozygotes observed in most of the breeds may be also indicative of the inbreeding derived from the small effective population sizes generally associated with cattle breeding.

We also performed a neutrality test for BoLA-DRB3 within each population. In contrast to what was described for other organisms, no excess of alleles is detected in intermediate frequencies, which would be expected if there were balancing selection. Previous results from other cattle breeds have shown variable results $(16,31,57)$. This variability may indicate that selective pressures acting since before domestication may not leave in detectable signatures in the current populations.

The $F_{S T}$ index shows significant differences across all cattle breeds. This is similar to previous results for Latin American breeds $(16,31)$. The differentiation levels are in accordance with what was expected considering the diverse origin of the breeds. Although Nellore and Brahman are both Bos indicus breeds, they have a very different historical and geographical origin. Whereas Nellore breed has its origins in India, Brahman was created in the United States from selected and directed crosses between zebu breeds (Guzerat, Nelore, Gyr, Krishna Valley and Sindhi Red). On the other hand, Brangus and Braford are the result of the crosses between Brahman with Angus or Hereford, respectively. The Creole bovine is the descendent of one brought by the conquerors to America, installed in the Caribbean and then scattered throughout the continent. This breed was mainly under natural selection for at least four centuries and it is a Bos taurus type.

It is known that individuals or populations having highly divergent BoLA-DRB3alleles will have a broader peptidebinding repertoire than those having very similar alleles $(62,63)$. In this sense, AMOVA analysis reveals that the differentiation between breeds is lower when analyzed at the sequence level. This indicates that the populations tend to have alleles more functionally similar; which can eventually decrease the response capacity.

The Nei's genetic distances are visualized by performing UPGMA trees and MDS analysis. The results of the analysis of both methods are concordant and show a strong distinction between Bos taurus and Bos indicus breeds. In the UPGMA tree, the closer distance between Braford and Brahman, with respect to Brangus, could indicate that the zebuine ancestor used for the creation of Braford was genetically different than the one used for Brangus since interms of evolutionary times, i. e. the timeframe is too short for the appearance of new alleles. The finding of alleles absent from the Brahman individuals in the mixed breeds may support this hypothesis but further studies are required.

Finally, the results obtained in the phylogenetic analysis performed by constructing Maximum Likelihood trees from $B O L A-D R B 3$ nucleotide sequences must be taken cautiously because bootstrap values are low, as expected when studying intraspecific variation. We did not find clusters that grouped alleles by breeds and alleles grouped according to their nomenclature as expected (33).

\section{Conclusions}

In conclusion, we have genetically characterized five bovine breedsof extensive use in northern Argentina and other subtropical regions of South America. The results show differences across all cattle populations and Braford is the 
breed with the highest genetic diversity. However, PBR sequence analysis at the aminoacid level shows no differences in functionality between populations, except for Braford. Altogether, these results could contribute to an ongoing effort to catalogue bovine MHC allele frequency according to breed and location. Moreover, the identification of the alleles present in these breeds could be of great help on the bioinformatic prediction of $\mathrm{T}$ cell epitopes for the rational design of vaccines for bovine tropical diseases.

\section{List Of Abbreviations}

MHC: Major Histocompatibility Complex

BoLA: Bovine Leukocyte Antigens

$\mathrm{dN}$ : number of nonsynonymous nucleotide substitutions per site

dS: number of synonymous nucleotide substitutions per site

PCC: Pearson Correlation Coefficients

MDS: Multidimensional Scaling

AMOVA: Analysis of Molecular Variance

HWE: Hardy-Weinberg equilibrium

ML: Maximum Likelihood

\section{Declarations}

\section{Ethics approval and consent to participate}

The animal study was reviewed and approved by the Institutional Committee for Care and Use of ExperimentalAnimals of the National Institute of Agricultural Technology (CICUAE-INTA). Protocol number $35 / 2010$.

\section{Consent for publication}

Not applicable

\section{Availability of data and material}

All data generated or analyzed during this study are included in this published article and its supplementary information files.

\section{Competing interests}

The authors declare that they have no competing interests.

\section{Funding}


This work was financially supported by grants from FONCYT-PICT 2018-2031, IAEACRPD3.10.28, INTA PE114 and INTA PE145.

\section{Authors' contributions}

MP and SW designed the study. MC and MV carried out experimental procedures. VL, MP, SW andMV analyzed the data. MV, VL and SW wrote the manuscript. All authors approved the final version of the manuscript.

\section{Acknowledgements}

The authors would like to thank Dr. Julia Sabio y García for English language editing.

\section{References}

1. United States Department of Agriculture. https://www.fas.usda.gov/data/livestock-and-poultry-world-marketsand-trade. Accessed 1 Feb 2021.

2. Utech KBW, Wharton RH, Kerr JD. Resistance to Boophilus microplus (Canestrini) in different breeds of cattle. Aust J Agric Res. 1978;29(4):885-95.

3. Bock R, Jackson L, De Vos A, Jorgensen W. Babesiosis of cattle. Parasitology. 2004;129.

4. Bohórquez MD, Ordoñez D, Suárez CF, Vicente B, Vieira C, López-Abán J, et al. Major Histocompatibility Complex Class II (DRB3) Genetic Diversity in Spanish Morucha and Colombian Normande Cattle Compared to Taurine and Zebu Populations. Front Genet. 2020;10(1):1-13.

5. Maccari G, Robinson J, Ballingall K, Guethlein LA, Grimholt U, Kaufman J, et al. IPD-MHC 2.0: An improved inter-species database for the study of the major histocompatibility complex. Nucleic Acids Res. 2017;45(D1):D860-4.

6. Davies CJ, Andersson L, Arriens MA, Bernoco D, Bissumbhar B, Byrns G, et al. Polymorphism of Bovine MHC Class II Genes. Joint Report of the Fifth International Bovine Lymphocyte Antigen (BoLA) Workshop, Interlaken, Switzerland, 1992. Int J Immunogenet. 1994;21(4):259-89.

7. Glass EJ, Oliver RA, Russell GC. Duplicated DQ Haplotypes Increase the Complexity of Restriction Element Usage in Cattle. J Immunol. 2000;165(1):134-8.

8. Baxter R, Hastings N, Law A, Glass EJ. A rapid and robust sequence-based genotyping method for BoLA-DRB3 alleles in large numbers of heterozygous cattle. Anim Genet. 2008;39(5):561-3.

9. Dietz AB, Cohen ND, Timms L, Kehrli ME. Bovine Lymphocyte Antigen Class II Alleles as Risk Factors for High Somatic Cell Counts in Milk of Lactating Dairy Cows. J Dairy Sci. 1997;80(2):406-12.

10. Maccari G, Robinson J, Bontrop RE, Otting N, de Groot NG, Ho CS, et al. IPD-MHC: nomenclature requirements for the non-human major histocompatibility complex in the next-generation sequencing era. Immunogenetics. 2018;70(10):619-23.

11. Takeshima SN, Matsumoto Y, Chen J, Yoshida T, Mukoyama H, Aida Y. Evidence for cattle major histocompatibility complex (BoLA) class II DQA1 gene heterozygote advantage against clinical mastitis caused by Streptococci and Escherichia species. Tissue Antigens. 2008;72(6):525-31.

12. Duangjinda M, Jindatajak Y, Tipvong W, Sriwarothai J, Pattarajinda V, Katawatin S, et al. Association of BoLADRB3 alleles with tick-borne disease tolerance in dairy cattle in a tropical environment. Vet Parasitol. 2013;196(3-4):314-20. 
13. Hedrick PW. Balancing selection and MHC. Genetica. 1998;104(3):207-14.

14. Brown JH, Jardetzky TS, Gorga JC, Stern LJ, Urban RG, Strominger JL, et al. Three-dimensional structure of the human class II histocompatibility antigen HLA-DR1. Nature. 1993;364(6432):33-9.

15. IPD-MHC BoLA page. https://www.ebi.ac.uk/ipd/mhc/allele/list/?group=BoLA. Accessed 1 Feb 2021.

16. Takeshima SN, Corbi-Botto C, Giovambattista G, Aida Y. Genetic diversity of BoLA-DRB3 in South American Zebu cattle populations. BMC Genet. 2018;19(1):1-13.

17. Miltiadou D, Law AS, Russell GC. Establishment of a sequence-based typing system for BoLA-DRB3 exon 2. Tissue Antigens. 2003;62(1):55-65.

18. Haplofinder. . Accessed 1 Feb 2021.

19. Notredame C, Higgins DG, Heringa J. T-coffee: A novel method for fast and accurate multiple sequence alignment. J Mol Biol. 2000;302(1):205-17.

20. Nei M. Estimation of average heterozygosity and genetic distance from a small number of individuals. Genetics. 1978;89(3):583-90.

21. Peakall R, Smouse PE. GENALEX 6: Genetic analysis in Excel. Population genetic software for teaching and research. Mol Ecol Notes. 2006;6(1):288-95.

22. Weir\&Cockerham. Estimating F-Statistics for the Analysis of Population Structure. Evolution (N Y). 1984;38(6):1358-70.

23. Rousset F. GENEPOP'007: A complete re-implementation of the GENEPOP software for Windows and Linux. Mol Ecol Resour. 2008;8(1):103-6.

24. Goudet FSTAT. (Version 1.2): A Computer Program to Calculate F-Statistics. J Hered. 1995;91(6):509-10.

25. Librado P, Rozas J. DnaSP v5: A software for comprehensive analysis of DNA polymorphism data. Bioinformatics. 2009;25(11):1451-2.

26. Tajima. Statistical Method for Testing the Neutral Mutation Hypothesis by DNA Polymorphism. Genetics. 1989;585-595.

27. Kimura. The Neutral Theory of Molecular Evolution. Cambridge Univ Press. 1983.

28. Kumar S, Stecher G, Li M, Knyaz C, Tamura K. MEGA X: Molecular evolutionary genetics analysis across computing platforms. Mol Biol Evol. 2018;35(6):1547-9.

29. R Core Team. R: A language and environment for statistical computing. R Found Stat Comput Vienna, Austria. 2020.

30. Da Mota AF, Gabriel JE, Martinez ML, Coutinho LL. Distribution of bovine lymphocyte antigen (BoLA-DRB3) alleles in Brazilian dairy Gir cattle (Bos indicus). Eur J Immunogenet. 2002;29(3):223-7.

31. Giovambattista G, Takeshima SN, Ripoli MV, Matsumoto Y, Franco LAA, Saito H, et al. Characterization of bovine MHC DRB3 diversity in Latin American Creole cattle breeds. Gene. 2013;519(1):150-8.

32. Kelly L, D’Angelo M, Nimo A, Piaggio J, Postiglioni A, Nicolini P, et al. Polimorfismo del gen DRB3.2 en bovinos criollos del Uruguay. Arch Zootec. 2003;52(197):77-80.

33. Davies CJ, Andersson L, Ellis SA, Hensen EJ, Lewin HA, Mikko S, et al. Nomenclature for factors of the BoLa system, 1996: Report of the ISAG BoLa Nomenclature Committee. Anim Genet. 1997;28(3):159-68.

34. Geneious P. 2020.2.4. https://www.geneious.com. Accessed 01 Feb 2021.

35. Suárez CF, Patarroyo ME, Trujillo E, Estupiñán M, Baquero JE, Parra C, et al. Owl monkey MHC-DRB exon 2 reveals high similarity with several HLA-DRB lineages. Immunogenetics. 2006;58(7):542-58. 
36. Crooks G, Hon G, Chandonia J, Brenner S. WebLogo: a sequence logo generator. Genome Res. 2004;14:118890.

37. Excoffier L, Smouse PE, Quattro JM. Analysis of Molecular Variance Inferred from Metric Distances among DNA Haplotypes: Application to Human Mitochondrial DNA. Genetics. 1992;131(2):479-91.

38. Excoffier L, Laval G, Schneider S. Arlequin (version 3.0): An integrated software package for population genetics data analysis. Evol Bioinforma. 2005;1:117693430500100.

39. Felsenstein j. PHYLIP- Phylogeny Inference Package (Version 3.2). Cladistics 5. 1989;164-6.

40. Rambaut A. FigTree v1.3.1. Instute of Evolutionary Biology. Edinburgh: University of Edinburgh; 2010.

41. Posada D, Crandall KA. MODELTEST: Testing the model of DNA substitution. Bioinformatics. 1998;14(9):8178.

42. Swofford DL. Phylogenetic analysis using parsimony (* and other methods). Version 4. Sinauer Assoc Sunderland. 2003.

43. Mikko S, Anderson L. Extensive MHC class II DRB3 diversity in African and European cattle. Immunogenetics. 1995;42(5):408-403.

44. Takeshima SN, Sarai Y, Saitou N, Aida Y. MHC class II DR classification based on antigen-binding groove natural selection. Biochem Biophys Res Commun [Internet]. 2009;385(2):137-42.

45. Takeshima SN, Matsumoto Y, Miyasaka T, Arainga-Ramirez M, Saito H, Onuma M, et al. A new method for typing bovine major histocompatibility complex class II DRB3 alleles by combining two established PCR sequence-based techniques. Tissue Antigens. 2011;78(3):208-13.

46. Maillard JC, Renard C, Chardon P, Chantal I, Bensaid A. Characterization of 18 new BoLA-DRB3 alleles. Anim Genet. 1999;30(3):200-3.

47. De S, Singh RK. Identification of new MHC-DRB3 alleles from Indian (Bos indicus) cattle. Anim Genet. 2006;37(6):605.

48. Xu A, van Eijk MJ, Park C, Lewin HA. Polymorphism in BoLA-DRB3 exon 2 correlates with resistance to persistent lymphocytosis caused by bovine leukemia virus. J Immunol. 1993;151(12):6977-85.

49. Mikko S, Spencer M, Morris B, Stabile S, Basu T, Stormont C, et al. A comparative analysis of MHV DRB3 polymorphism in the American bison (Bison bison). J Hered. 1997;88(6):499-503.

50. Gelhaus A, Schnittger L, Mehlitz D, Horstmann RD, Meyer CG. Sequence and PCR-RFLP analysis of 14 novel BOLA-DRB3 alleles. 1995;147-53.

51. Takeshima SN, Saitou N, Morita M, Inoko H, Aida Y. The diversity of bovine MHC class II DRB3 genes in Japanese Black, Japanese Shorthorn, Jersey and Holstein cattle in Japan. Gene. 2003;316(1-2):111-8.

52. Takeshima SN, Ikegami M, Morita M, Nakai Y, Aida Y. Identification of new cattle BoLA-DRB3 alleles by sequence-based typing. Immunogenetics. 2001;53(1):74-81.

53. Sitte K, East IJ, Lavin MF, Jazwinska EC. Identification and characterization of new BoLA-DRB3 alleles by heteroduplex analysis and direct sequencing. Anim Genet. 1995;26(6):413-7.

54. Das DN, Sri Hari VG, Hatkar DN, Rengarajan K, Saravanan R, Suryanarayana VVS, et al. Genetic diversity and population genetic analysis of bovine MHC class II DRB3.2 locus in three Bos indicus cattle breeds of Southern India. Int J Immunogenet. 2012;39(6):508-19.

55. Baxter R, Craigmile SC, Haley C, Douglas AJ, Williams JL, Glass EJ. BoLA-DR peptide binding pockets are fundamental for foot-and-mouth disease virus vaccine design in cattle. Vaccine. 2009;28(1):28-37. 
56. Bolaños I, Hernandez D, Alvarez L. Asociación de los alelos del gen BoLA-DRB3 con la infección natural de Babesia spp en el ganado criollo Hartón del Valle. Arch Zootec. 2017;66(253):113-20.

57. Takeshima SN, Giovambattista G, Okimoto N, Matsumoto Y, Rogberg-Muñoz A, Acosta TJ, et al. Characterization of bovine MHC class II DRB3 diversity in South American Holstein cattle populations. Tissue Antigens. 2015;86(6):419-30.

58. Ou D, Mitchell LA, Décarie D, Tingle AJ, Lacroix M, Zrein M. Point mutation of a rubella virus E1 protein T-cell epitope by substitution of single amino acid reversed the restrictive HLA-DR polymorphism: A possible mechanism maintaining HLA polymorphism. Viral Immunol. 1998;11(2):93-102.

59. García-Briones MM, Russell GC, Oliver RA, Tami C, Taboga O, Carrillo E, et al. Association of bovine DRB3 alleles with immune response to FMDV peptides and protection against viral challenge. Vaccine. 2000;19(910):1167-71.

60. Carignano HA, Beribe MJ, Caffaro ME, Amadio A, Nani JP, Gutierrez G, et al. BoLA-DRB3 gene polymorphisms influence bovine leukaemia virus infection levels in Holstein and Holstein $\times$ Jersey crossbreed dairy cattle. Anim Genet. 2017;48(4):420-30.

61. Rastislav M, Mangesh B. BoLA-DRB3 exon 2 mutations associated with paratuberculosis in cattle. Vet J. 2012;192(3):517-9.

62. Klein J, Sato A, Nikolaidis N. MHC, TSP, and the origin of species: From immunogenetics to evolutionary genetics. Annu Rev Genet. 2007;41:281-304.

63. Lenz TL, Mueller B, Trillmich F, Wolf JBW. Divergent allele advantage at MHC-DRB through direct and maternal genotypic effects and its consequences for allele pool composition and mating. Proc R Soc B Biol Sci. 2013;280:1762.

\section{Figures}




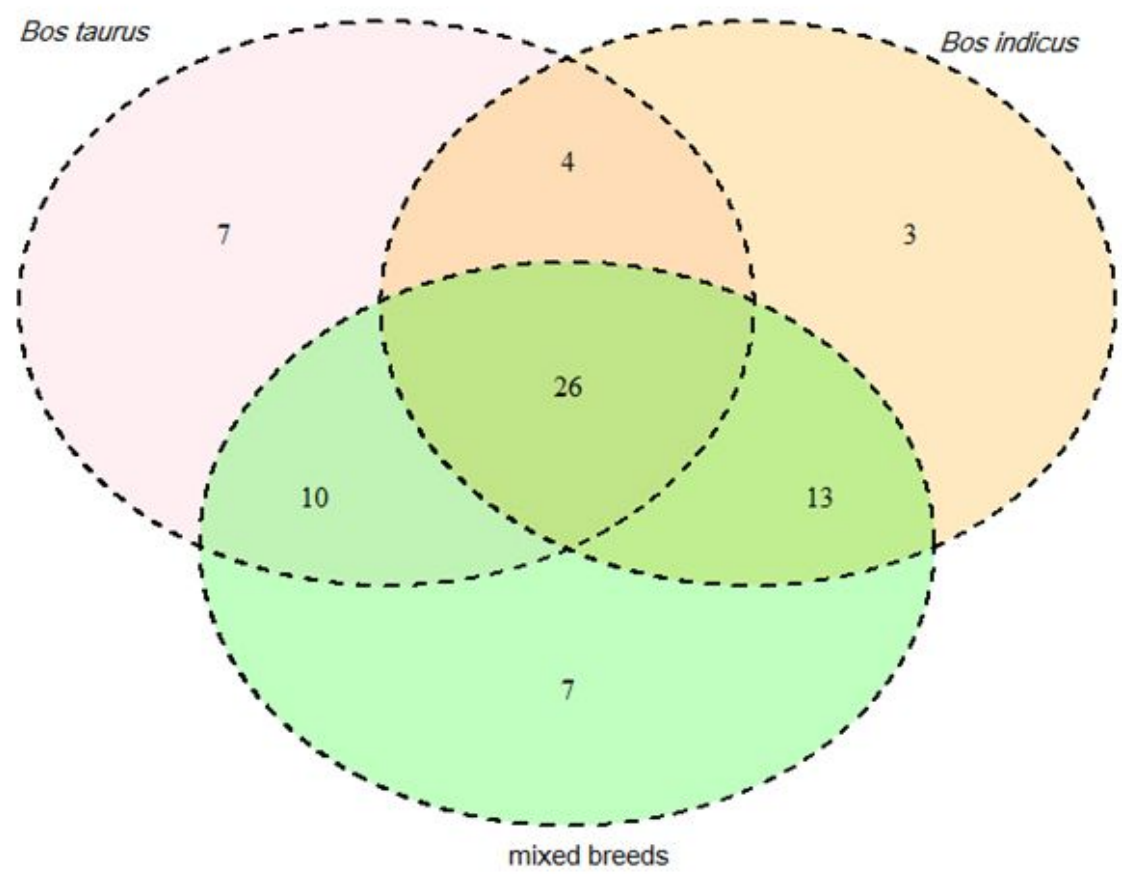

Figure 1

Venn diagram showing BoLA-DRB3 allele distribution among cattle breeds according to their major type: Bos Taurus, Bos indicus and mixed breeds.

(A)

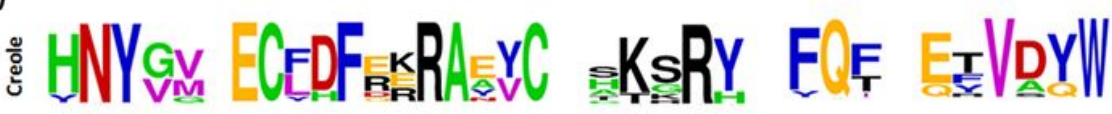

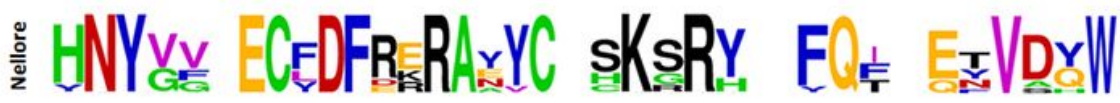

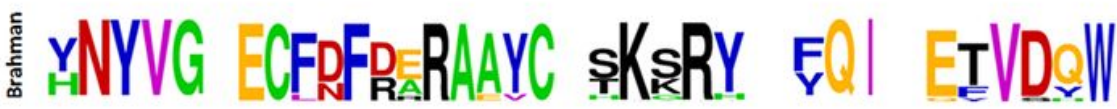

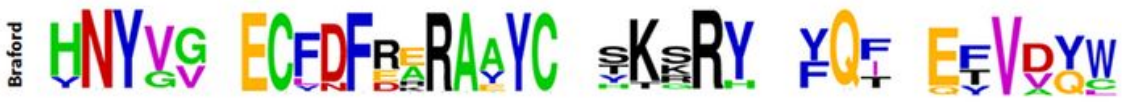

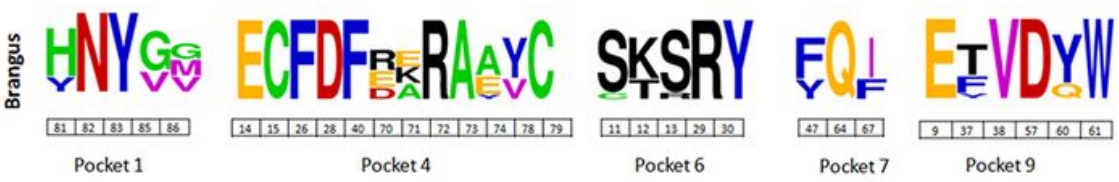

(B)

$\begin{array}{rrrrrr} & \text { Creole } & \text { Nellore } & \text { Brahman } & \text { Braford } & \text { Brangus } \\ \text { Creole } & 1 & 0.943 & 0.905 & 0.965 & 0.965 \\ \text { Nellore } & 0.943 & 1 & 0.907 & 0.944 & 0.944 \\ \text { Brahman } & 0.905 & 0.907 & 1 & 0.947 & 0.931 \\ \text { Braford } & 0.965 & 0.944 & 0.947 & 1 & 0.973 \\ \text { Brangus } & 0.965 & 0.944 & 0.931 & 0.973 & 1\end{array}$

(C)

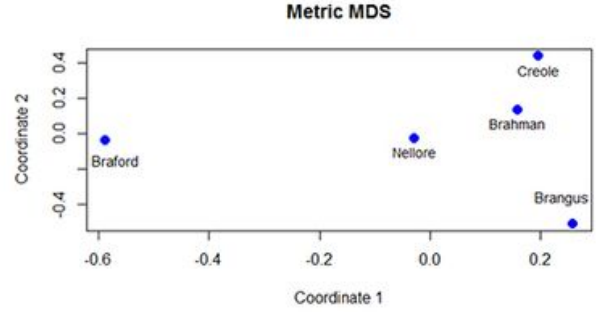


Figure 2

PBR analysis. (A) Peptide-binding region logos, (B) Pearson correlation coefficients among breeds and (C) metric MDS based on BoLA-DRB3 pocket position variability among populations. (B) shows identical values above and below the diagonal.

(A)

\begin{tabular}{|r|r|r|r|r|r|}
\hline & Creale & Nellore & Brahman & Braford & Brangus \\
\hline Creove & 0.000 & 0.076 & 0.117 & 0.036 & 0.034 \\
\hline Nellore & 1.505 & 0.000 & 0.091 & 0.040 & 0.070 \\
\hline Brahman & 2.355 & 0.854 & 0.000 & 0.058 & 0.081 \\
\hline Braford & 0.887 & 0.596 & 0.483 & 0.000 & 0.029 \\
\hline Brangus & 0.566 & 1.305 & 0.897 & 0.631 & 0.000 \\
\hline
\end{tabular}

(B)

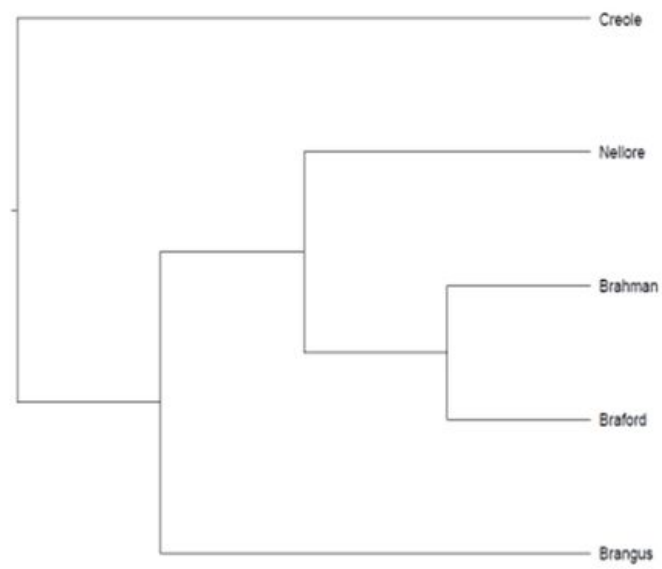

(C)

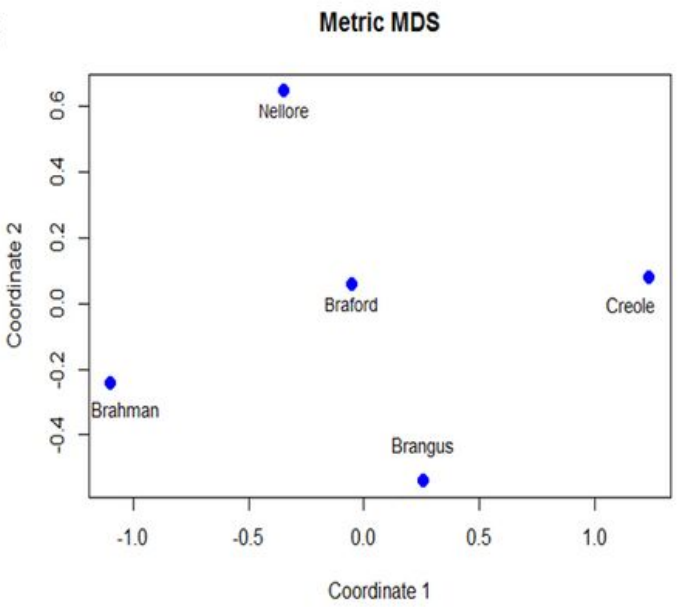

Figure 3

Population structuring and relationship. (A) Genetic distance between pairs of breeds estimated by Wright's $F$ statistics (FST) (above) and Nei's DA distance (below) (B) Nei's distance tree (C) Metric multidimensional scaling analysis (MDS) of BoLA-DRB3 genotypes in five cattle breeds. 


\section{Supplementary Files}

This is a list of supplementary files associated with this preprint. Click to download.

- Additionalfile1.docx

- Additionalfile2.docx

- Additionalfile3.docx

- Additionalfile4.docx

- Additionalfile5.pptx 